\title{
EXPRESSÃO IMUNO-HISTOQUÍMICA DOS MARCADORES PCNA, Ki67 E P53 EM CARCINOMAS EPIDERMÓIDES DO TRATO AERODIGESTIVO SUPERIOR
}

\author{
IMMUNOHISTOCHEMICAL EXPRESSION OF MARKERS PCNA, Ki67 AND P53 IN \\ SQUAMOUS CELL CARCINOMAS OF UPPER AERODIGESTIVE TRACT
}

\author{
João Paulo Esposito, ACBC-SP ${ }^{1}$ \\ Roberto Souza Camargo, TCBC-SP2 \\ Adhemar Longatto Filho ${ }^{3}$ \\ Celso di Loreto ${ }^{4}$ \\ Cristina Takami Kanamura ${ }^{3}$ \\ Erasmo Magalhães Castro de Tolosa, TCBC-SP ${ }^{5}$
}

\begin{abstract}
RESUMO: Objetivo: Os carcinomas epidermóides do trato aerodigestivo superior são tumores de comportamento biológico heterogêneo. O objetivo deste trabalho é verificar se a expressão imuno-histoquímica dos marcadores Ki67, PCNA e P53 apresenta correlações com parâmetros prognósticos clínico-patológicos. Métodos: Determinação da expressão imuno-histoquímica dos antígenos Ki67, PCNA e P53 em espécimes tumorais fixados e embebidos em parafina de 53 pacientes com carcinoma epidermóide em diferentes sítios primários do trato aerodigestivo superior. Resultados: Os marcadores tiveram altos índices de expressão imuno-histoquímica, sendo 46,5\% para o Ki67, 66,5\% para o PCNA e 36,5\% para o P53. Não houve correlação da expressão do Ki67 e do PCNA com o estadiamento TNM (AJCC), nem com o grau de malignidade. A expressão do Ki67 apresentou correlação positiva com a expressão do PCNA ( $p=0,037)$. O mesmo aconteceu

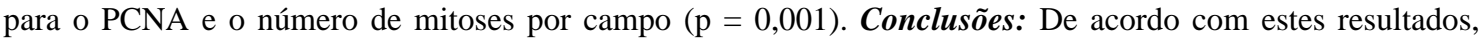
concluiu-se que a determinação da imunorreatividade dos marcadores Ki67 e PCNA é um método objetivo e quantificável para avaliar proliferação celular que pode subsidiar as informações prognósticas.
\end{abstract}

Descritores: Carcinoma de células escamosas; Marcadores biológicos de tumor; Proteína P53; Antígeno Ki67; Antígeno nuclear de célula em proliferação.

\section{INTRODUÇÃO}

Os carcinomas de células escamosas ou epidermóides do trato aerodigestivo superior são as neoplasias malignas mais freqüentes em países como Índia e China, estimando-se aproximadamente 500.000 casos novos anualmente em todo o mundo ${ }^{1}$. No Brasil, tumores de boca, por exemplo, têm uma estimativa anual de 8.000 casos novos ${ }^{2}$.
Os critérios utilizados para a avaliação prognóstica dessas neoplasias são baseados essencialmente no TNM (AJCC/UICC), no sítio primário da lesão, na idade e nas características histopatológicas, como o grau de diferenciação celular de Broders ${ }^{3-5}$.

Entretanto, tais parâmetros são muito subjetivos e o comportamento biológico dos carcinomas epidermóides é variável, havendo tumores em um mesmo estádio com evoluções discrepantes ${ }^{6}$. Logo, há necessidade de novos mé-

1. Doutor em Medicina pela FMUSP, Médico Assistente da Clínica Cirúrgica do Hospital Universitário da USP

2. Professor Associado da Disciplina de Técnica Cirúrgica e Cirurgia Experimental da FMUSP

3. Pesquisador da Divisão de Patologia do Instituto Adolfo Lutz

4. Médico Patologista da Divisão de Patologia do Instituto Adolfo Lutz

5. Professor Titular da Disciplina de Técnica Cirúrgica e Cirurgia Experimental da FMUSP

Recebido em 1/3/99

Aceito para publicação em 25/7/2000

Trabalho realizado na Disciplina de Técnica Cirúrgica e Cirurgia Experimental da Faculdade de Medicina da Universidade de São Paulo — FMUSP, Hospital Universitário da USP e da Divisão de Patologia do Instituto Adolfo Lutz. 
todos objetivos e quantificáveis que permitam reconhecer o comportamento biológico individual desses tumores.

A proliferação celular é uma característica do fenótipo maligno que pode ser avaliada pela expressão imunohistoquímica de marcadores como o PCNA e o Ki67 7,8.

O PCNA ou antígeno nuclear de proliferação celular é um auxiliar da DNA-polimerase-delta que atua na replicação e também no reparo de moléculas de DNA lesadas através da excisão de nucleotídeos, formando um complexo quaternário com a proteína P21, a ciclina D e a CDK (quinase dependente de ciclina) ${ }^{9}$.

Nas fases G1, G2 e M do ciclo celular, a expressão imuno-histoquímica do PCNA é reduzida, contudo aumenta até sete vezes na fase $S^{10}$.

Já o Ki67 é um antígeno nuclear não-histona que faz parte da estrutura protéica conhecida como suporte cromossômico. Sua expressão é determinada pelo gene situado no locus $10 \mathrm{q} 25$ e ocorre no final da fase $\mathrm{G} 1$, em S, G2 e $\mathrm{M}^{11}$.

Além da proliferação celular, o comportamento biológico das neoplasias pode ser determinado pela presença de antígenos de supressão tumoral, como o P53, que é uma fosfoproteína nuclear de $53 \mathrm{kD}$ cuja função é de "Guardião do Genoma", impedindo a progressão do ciclo celular na transição G1/S, na presença de danos à molécula de DNA ${ }^{12}$.

A expressão imuno-histoquímica da proteína P53, em geral, ocorre por seu acúmulo decorrente da mutação do gene P53, havendo conseqüente perda da sua função tumor-supressora ${ }^{13}$.

O objetivo do nosso estudo é correlacionar a expressão imuno-histoquímica dos marcadores de proliferação PCNA e Ki67 e de supressão tumoral P53, com parâmetros prognósticos clínicos e patológicos em carcinomas epidermóides do trato aerodigestivo superior, no sentido de subsidiar seu estadiamento.

\section{MÉTODO}

Foi selecionado um grupo de 53 pacientes portadores de carcinomas epidermóides do trato aerodigestivo superior, sendo $43(81,13 \%)$ do sexo masculino, com idade variando entre 34 e 80 anos (média $=57,5$ anos). Destes, $88,46 \%$ eram tabagistas e $61,53 \%$, etilistas.

Cada paciente apresentava um único tumor primário com a seguinte distribuição por localização: glote -14 (26,41\%), supraglote e hipofaringe - 13 (24,52\%), língua -9 $(16,98 \%)$, assoalho da boca $-8(15,09 \%)$, lábio $-5(9,43 \%)$, orofaringe $-3(5,66 \%)$ e retromolar $-1(1,88 \%)$.

O estadiamento clínico desses tumores pelo TNM apresentava diferenças, tendo a seguinte distribuição: estádio $\mathrm{I}-\mathrm{n}=9(16,98 \%)$, estádio II $-\mathrm{n}=10(18,86 \%)$, estádio III $-\mathrm{n}=15(28,30 \%)$, estádio IV $-\mathrm{n}=19(35,84 \%)$.

Todos os pacientes foram submetidos ao tratamento cirúrgico com intuito curativo no Hospital Universitário da USP entre 1986 e 1996, em 85\% dos casos pela mesma equipe cirúrgica.

Os espécimes tumorais foram obtidos previamente à radioterapia e quimioterapia, sendo colocados em solução de formalina a $10 \%$ e embebidos em parafina.
Nos cortes corados pela hematoxilina-eosina, foram determinados por um único patologista (C.L.) o grau de diferenciação celular de Broders e o grau de malignidade histológica segundo a classificação de Anneroth et al ${ }^{14}$, modificada por De Araújo et al ${ }^{15}$. Neste, foram determinados seis parâmetros: queratinização, pleomorfismo nuclear, número de mitoses por campo, infiltrado linfoplasmocitário, estádio de invasão e padrão de invasão. Cada parâmetro foi graduado de 1 a 4 e a somatória destes representou o grau de malignidade.

Os cortes histológicos fixados e embebidos em parafina, com $3 \mathrm{~mm}$, foram colocados em lâminas silanizadas (3Aminopropiltrietoxisilano).

O procedimento imuno-histoquímico obedeceu ao seguinte roteiro: 1 - desparafinização a $60^{\circ} \mathrm{C}(20$ minutos); 2 - desparafinização à temperatura ambiente (30 minutos); 3 - hidratação com álcool e água; 4 - recuperação antigênica: aquecimento das lâminas em solução de ácido cítrico $0,01 \mathrm{M} / \mathrm{pH}=6,0 \mathrm{em}$ forno microondas (potência máxima) para o PCNA e P53 (10 minutos), e em panela de pressão para o Ki67 (5 minutos); 5 - bloqueio da peroxidade endógena em dois banhos de $\mathrm{H}_{2} \mathrm{O}_{2}$ a $3 \%$ (10 minutos cada) e lavagem com água e em tampão PBS (solução salina tamponada com fosfatos); 6 - incubação com anticorpo específico (primário) em câmara úmida a $4^{\circ} \mathrm{C}$ (18 horas): para o Ki67, PC10 para o PCNA e DO-7 para o P53; 7 - incubação com anticorpo biotinilado (secundário) em câmara úmida a $37^{\circ} \mathrm{C}$ (30 minutos), mais lavagens em PBS; 8 - incubação com complexo estreptavidina-biotina-peroxidade em câmara úmida $\left(37^{\circ} \mathrm{C}\right)$ por 30 minutos, mais lavagens em PBS; 9 revelação por imersão em solução de diaminobenzidina $60 \mathrm{mg} \%$ em tampão PBS contendo $0,06 \%$ de peróxido de hidrogênio, mais lavagens em água destilada; 10 - contracoloração em hematoxilina de Harris, desidratação em álcool e montagem em lamínula com Entellan.

Os núcleos positivos para cada um dos marcadores apresentaram típica coloração marrom. Como controle negativo foram empregadas lâminas sem o uso de anticorpos específicos. Como controles positivos foram usados exemplares de carcinoma de mama (para o Ki67 e P53) e adenocarcinoma gástrico (para o PCNA).

As lâminas foram lidas por um único pesquisador (A.L.), que escolheu uma área representativa, preferencialmente na periferia do tumor (HOT SPOT) e com aumento de $400 \mathrm{X}$, contou com 200 células tumorais definindo a porcentagem de núcleos positivos.

A correlação paramétrica de Pearson foi adotada como método estatístico, tomando-se como nível significativo $5 \%(\mathrm{P} \leq 0,05)$.

Foram feitas as correlações do grupo como um todo e também de dois subgrupos: grupo A (tumores de laringe e hipofaringe, $\mathrm{n}=27$ ) e grupo $\mathrm{B}$ (tumores de cavidade oral e orofaringe, $n=26$ ).

\section{RESULTADOS}

Após a confirmação histológica, o estadiamento pTpNpM (AJCC) apresentou diferenças entre os dois grupos: grupo A - Estádio I - $\mathrm{n}=2(7,4 \%)$, Estádio II - $\mathrm{n}$ $=5(18,5 \%)$, Estádio III $-\mathrm{n}=13(48,14 \%)$, Estádio IV $-\mathrm{n}=$ 
$7(25,92 \%)$. Grupo B .- Estádio I - n = $7(26,90 \%)$, Estádio II $-\mathrm{n}=5(19,20 \%)$, Estádio III - n = $2(7,7 \%)$, Estádio IV $\mathrm{n}=12(46,10 \%)$.

Para a avaliação histológica, dois espécimes não foram adequados para a determinação do grau de malignidade, sendo excluídos.

$\mathrm{Na}$ determinação do grau de diferenciação de Broders, obtivemos: grupo A - grau II - $\mathrm{n}=15$ ( 60\%), grau III $-\mathrm{n}=10(40 \%)$; grupo B - grau II $-\mathrm{n}=16(61,53 \%)$, grau III $-\mathrm{n}=10(38,46 \%)$; grupo total - grau II $-\mathrm{n}=31(60,78 \%)$, grau III $-\mathrm{n}=20(39,21 \%)$.

A somatória de pontos do grau de malignidade histológica variou de 8 a 18 pontos, com médias de 14,40 (grupo A), 14,46 (grupo B) e 14,43 (grupo total).

A expressão imuno-histoquímica do Ki67 variou de $5,5 \%$ a $95 \%$ dos núcleos contados, com médias de $58,5 \%$ no grupo A, $35 \%$ no grupo B e $46,5 \%$ no grupo total. Todos os espécimes tumorais expressaram Ki67.

O PCNA também teve expressão em todos os espécimes, variando de $10,5 \%$ a $98 \%$ dos núcleos contados, com médias de $69 \%$ no grupo A, $64 \%$ no grupo B e $66,5 \%$ no grupo total.

Já o P53 teve expressão em 44 tumores $(86,27 \%)$, com positividade variando de $0,5 \%$ a $96,5 \%$, cujas médias de expressão foram $37 \%$ (grupo A), 35,5\% (grupo B) e 36,5\% (grupo total).

Idade, sexo, tabagismo e etilismo não apresentaram qualquer correlação estatística significante. Nem a expressão de PCNA, nem a expressão do Ki67, apresentaram correlações com o estadiamento pelo TNM ou com o grau de malignidade e grau de diferenciação celular.

A expressão de Ki67 teve correlação com o sítio primário, sendo maior nos tumores do grupo A (laringe + hipofaringe).

Todas as correlações com significância estatística são apresentadas na Tabela 1 .

\section{DISCUSSÃO}

Tanto a avaliação prognóstica quanto a escolha terapêutica representam tarefas difíceis nos carcinomas epidermóides do trato aerodigestivo superior, pois estes são neoplasias de comportamento biológico individual bastante variável ${ }^{16}$.

Com o intuito de aprimorar os métodos de estadiamento com informações objetivas e quantificáveis, estudamos a expressão imuno-histoquímica dos marcadores de proliferação celular PCNA e Ki67 e do antígeno de supressão tumoral P53 em 53 carcinomas primários de trato aerodigestivo superior.

Para as correlações entre os parâmetros prognósticos, analisamos o grupo como um todo e dois subgrupos (A e B), de acordo com a topografia, semelhança na história natural e drenagem linfática, como já descrito na literatura ${ }^{6}$.

Os espécimes tumorais apresentaram elevados índices de expressão imuno-histoquímica para os três marcadores, comparando-se aos achados de outros autores ${ }^{5,17}$. Atribuímos tal fato à metodologia imuno-histoquímica uti-
Tabela 1

Correlações com significância estatística

\begin{tabular}{|c|c|c|c|}
\hline & Total & Grupo A & Grupo B \\
\hline $\begin{array}{l}\text { T(AJCC) X } \\
\text { N(AJCC) }\end{array}$ & $P=0,044$ & $\mathrm{P}=0,035$ & NS \\
\hline $\begin{array}{l}\text { N(AJCC) X } \\
\text { Est. invasão }\end{array}$ & $\mathrm{P}=0,038$ & NS & $\mathrm{P}=0,023$ \\
\hline $\begin{array}{l}\text { TNM(AJCC) X } \\
\text { Est. invasão }\end{array}$ & $\mathrm{P}=0,003$ & NS & $\mathrm{P}=0,005$ \\
\hline $\begin{array}{l}\text { TNM(AJCC) X } \\
\text { Grau malig. }\end{array}$ & $\mathrm{P}=0,043$ & NS & NS \\
\hline $\begin{array}{l}\text { Grau malig. X } \\
\text { Broders }\end{array}$ & $\mathrm{P}=0,000$ & $\mathrm{P}=0,012$ & $\mathrm{P}=0,002$ \\
\hline $\begin{array}{l}\text { Ki } 67 \quad \text { X } \\
\text { Topografia }\end{array}$ & $\mathrm{P}=0,004$ & NS & NS \\
\hline $\begin{array}{l}\text { Ki } 67 \mathrm{X} \\
\text { PCNA }\end{array}$ & $\mathrm{P}=0,037$ & NS & $\mathrm{P}=0,034$ \\
\hline $\begin{array}{l}\text { Ki } 67 \text { X } \\
\text { Mitoses }\end{array}$ & NS & NS & $\mathrm{P}=0,048$ \\
\hline $\begin{array}{l}\text { PCNA X } \\
\text { Mitoses }\end{array}$ & $\mathrm{P}=0,001$ & $\mathrm{P}=0,000$ & NS \\
\hline $\begin{array}{l}\text { P53 X } \\
\text { Ki } 67\end{array}$ & NS & NS & $\mathrm{P}=0,042$ \\
\hline $\begin{array}{l}\text { P53 X } \\
\text { TNM(AJCC) }\end{array}$ & NS & $\mathrm{P}=0,022$ & NS \\
\hline
\end{tabular}

NS - não significativo.

lizada com a aplicação de aquecimento em forno microondas ou panela de pressão para recuperação antigênica ${ }^{18}$.

Outro detalhe relevante foi a concentração da avaliação na periferia tumoral, onde ocorre maior proliferação celular. No núcleo tumoral, por outro lado, há hipocelularidade, queratinização e necrose ${ }^{19}$.

Contudo, a explicação mais significativa para os altos índices de expressão é o bom estado de conservação dos espécimes tumorais, pois a rotina do serviço de patologia do HU-USP não possibilita a permanência prolongada dos espécimes em solução de formol, o que levaria a uma redução ou até anulação da expressão dos antígenos ${ }^{20}$.

No estudo das correlações estatísticas houve significância positiva entre o TNM e o grau de malignidade histológica de Anneroth ${ }^{14}$ modificado por De Araújo ${ }^{15}$. Tal achado nos faz crer que o uso concomitante desses sistemas de estadiamento pode potencializar as informações prognósticas, como também foi observado por Welkoborsky ${ }^{21}$. Esta suposição ganha mais respaldo, quando observamos as cor- 
relações positivas que obtivemos entre $\mathrm{T}$ e $\mathrm{N}$ e entre estádio de invasão histológica e N (AJCC).

A expressão Ki67 mostrou correlação com o sítio do tumor primário, apresentando índices mais elevados nos tumores do grupo A (laringe + hipofaringe). A explicação para esse fato poderia ser o predomínio de estádios III e IV nesse grupo, com tumores mais proliferativos.

Entretanto, nem Ki67 nem PCNA mostraram correlação com o TNM ou grau de malignidade, achado semelhante ao de outros autores ${ }^{17,22}$.

Tal evento poderia ser explicado pela ausência de relação direta entre proliferação celular e capacidade de formar metástases, que são características independentes do fenótipo maligno.

$\mathrm{Na}$ análise de cada parâmetro do grau de malignidade, o único a se correlacionar positivamente com a expressão de PCNA foi o número de mitoses por campo.

Este achado reforça a eficácia do PCNA como indicador de proliferação celular ${ }^{23}$.

Ademais, a expressão do Ki67 também teve correlação positiva com a expressão de PCNA, apontando para esses marcadores como um método objetivo e quantificável mais sensível e específico que a contagem do número de mitoses na histologia.

Os índices de PCNA foram mais elevados do que os de Ki67 em cada espécime estudado, fato explicável pela meia-vida de até 20 horas do primeiro antígeno ${ }^{24}$.

Já a expressão do P53 somente apresentou correlação positiva com o TNM (AJCC) nos tumores do grupo A (faringe e hipofaringe), no qual houve predomínio de estádios III e IV. Poderíamos atribuir tal achado ao acúmulo de mutações que ocorre ao longo da evolução tumoral.

Além do mais, nos tumores do grupo B (boca e orofaringe) houve correlação positiva entre expressão de P53 e de Ki67, sugerindo que a perda da função supressora do P53 permite a proliferação celular descontrolada, com conseqüente acúmulo de Ki67²5.

Portanto, a imuno-histoquímica revelou-se um método eficiente para avaliar a proliferação celular em carcinomas epidermóides do trato aerodigestivo superior, principalmente realizando-se a determinação dos índices de PCNA e Ki67 em número absoluto de núcleos marcados, sem nenhum tipo de agrupamento baseado em critérios subjetivos, em concordância com autores como Vijeyasingam et $\mathrm{al}^{26}$ e Spafford et $\mathrm{al}^{27}$.

Se, por um lado, a determinação precisa da capacidade de proliferação celular não pode predizer se haverá ou não metástases, por outro, pode oferecer informações sobre radiossensibilidade e quimiossensibilidade, lembrando-se que tumores altamente proliferativos são, em geral, mais sensíveis aos agentes citotóxicos ${ }^{28}$.

No que tange ao P53, ainda permanecemos duvidosos quanto ao seu real valor prognóstico, o que é compatível com os resultados contraditórios apresentados na literatura $^{29,30}$.

Com base nos resultados deste trabalho, podemos concluir que a determinação imuno-histoquímica do Ki67 e PCNA pode subsidiar as informações prognósticas do TNM (AJCC) e do grau de malignidade histológico, como eficientes indicadores de proliferação celular.

\begin{abstract}
Background: Squamous cell carcinomas of upper aerodigestive tract are tumors with heterogeneous biological behaviour. The aim of present study is to assess whether any correlation exists between immunohistochemical expression of Ki67, PCNA and P53 markers and clinicopathologic parameters. Methods: Immunohistochemical determination of Ki67, PCNA and P53 antigens in fixated and paraffinembedded tumour especimens from 53 patients with squamous cell carcinoma in different primary locations of upper aerodigestive tract. Results: The markers had high evidence average rates with 46,5\% for Ki67, 66,5\% for PCNA and 36,5\% for P53. There was neither correlation of Ki67 and PCNA evidence nor with TNM staging nor with malignancy degree. The expression of Ki67 demonstrated correlation with the expression of PCNA ( $p=0,037)$. The same ocurred to PCNA and the number of mitoses $(p=$ 0,001). Conclusions: According to these results, it has been concluded that the determination of immunoreactivity of Ki67 and PCNA proliferation markers is an accurate and quantitative method which may provide prognostic information.
\end{abstract}

Key Words: Squamous cell carcinoma; Tumour markers; P53protein; Ki67; Proliferating cell nuclear antigen.

\section{REFERÊNCIAS}

1. Boring CC, Squires TS, Tong T. Cancer statistics, 1992. CA Cancer J Clin 1992; 42:19-38.

2. Abib AR, Abreu E, Rebelo MS et al. Estimativa da incidência e mortalidade por câncer no Brasil. Instituto Nacional do Câncer 1997.
3. Broders AC. Squamous cell epithelioma of the lip. J Am Med Assoc 1920; 74:656-664.

4. Koch WM, Brennan J, Zahurak M et al. P53 mutation and locoregional treatment failure in head and neck squamous cell carcinoma. J Nat Cancer Inst 1996; 88(21):15801-15805.

5. Roland NJ, Caslin AW, Bowie GL et al. Has the cellular proliferation marker Ki67 any clinical relevance in squa- 
mous cell carcinoma of the head and neck? Clin Otolaryngol 1994; 19:13-18.

6. Janot F, Klinjanienko J, Russo A et al. Prognostic value of clinicopathological parameters in head and neck squamous cell carcinoma: a prospective analysis. $\mathrm{Br} \mathbf{J}$ Cancer 1996; 73:531-538.

7. Sawhney N, Hall PA. Ki67 structure, function and new antibodies. J Pathol 1992; 168:161-162.

8. Baserga R. Growth regulation of the PCNA gene. J Cell Science 1991; 98:433-436.

9. Xiong Y, Zhang H, Beach D. D type cyclins associate with multiple protein kinases and the DNA replication and repair factor PCNA. Cell 1992; 71:505-514.

10. Prelich G, Tan CK, Kostura M et al. Functional identity of proliferating cell nuclear antigen and a DNA-polymerase delta. Nature 1987; 326(2):517-520.

11. Fonatsch C, Duchrow M, Rieder, MH et al. Assignament of the human Ki67 genes (MK 167) to 10q25-qter. Genomics 1991; 11:476-477.

12. Levine AJ, Perry M E, Chang A et al. The role of the P-53 tumor suppressor gene in tumorigenesis. Br J Cancer 1994; 69:409-416.

13. Shaw PH. The role of P53 in cell cycle regulation. Path Res Pract 1996;192:669-675.

14. Anneroth G, Hansen LS, Silverman S. Malignancy grading in oral squamous cell carcinoma. J Oral Pathol 1986; 15:162-168.

15. De Araújo VC, Loyola AM, Santos Pinto DD et al. P53 in biopsies of oral squamous cell carcinoma. A comparative study with a malignance grading system. Oral Oncology 1997; 33(1):5-9.

16. Barona De Guzman R, Martorell MA, Basterra J et al. Prognostic value of histopathological parameters in $51 \mathrm{su}-$ praglotic squamous cell carcinomas. Laryngoscope 1993; 103:538-540.

17. Tomasino RM, Daniele E, Bazan V et al. Prognostic significance of cell kinetics in laryngeal squamous cell carcinoma: Clinicopathological Associations. Cancer Res 1995; 55:6103-6108.

18. Piffko J, Bankfalvi A, Öfner D et al. Immunohistochemical Detection of P53 Protein in archival Tissues from squamous cell carcinomas of the oral cavity using wet autoclave antigen Retrieval. J Pathol 1995; 176:69-75.

19. Van Direndonck JH, Keijzer R, Velde J et al. Nuclear distribution of Ki67 during the cell cycle comparison with growth fraction in human breast cancer cells, Cancer Res 1989; 49:2999-3006.

20. Morisaki Y, Shima S, Yoshizumi Y et al. PCNA immunostaining combined with agnor staining in esophageal squamous cell carcinoma to identify patients with a poor prognosis. Surg Today. Jpn J Surg 1995; 25:389-395.

21. Welkoborsky HJ, Hinni M, Dienes HP et al. Predicting recurrence and survival in patients with laryngeal cancer by means of DNA cytometry, tumor front grading, and proliferation markers. Ann Otol Rhinol Laryngol 1995; 104:503-509.

22. Jones AS, Roland NJ, Caslin AW et al. Comparison of cellular proliferation markers in squamous cell carcinoma of the head and neck. J Laryngol Otol 1994; 108:859864.

23. Kobayashi I, Matsuo K, Ozeki Y et al. The Proliferative activity in oral epithelial dysplasia analyzed by proliferating cell nuclear antigen immonostaining and argyrophilic nucleolar organizer region staining. Hum Pathol 1995; 26:907-913.
24. Bravo R, Bravo HM. Existence of two populations of cyclin/proliferating cell nuclear antigen during the cell cycle: association with DNA replications sites. J Cell Biol 1987; 105:1549-1554

25. Slootweg PJ, Koole R, Kordijk GJ. The presence of P53 protein in relation to Ki67 as celular proliferation marker in head and neck squamous cell carcinoma and adjacent dysplastic mucosa. Oral Oncol, Eur J Cancer 1994; 308(2):138-141.

26. Vijeyasingam R, Darnton SJ, Jenner K, et al - Expression of $\mathrm{P}-53$ proteins in oesophageal carcinoma: Clinicopathological correlation and prognostic significance. $\mathrm{Br} \mathrm{J}$ Surg 1994; 81:1623-1626.

27. Spafford MF, Koeppe J, Pan Z et al. Correlation of tumors markers P53, bcl-2, CD34, CD44H, CD44V6 and Ki67 with survival and metastasis in laryngeal squamous cell carcinoma. Arch Otolaryngol Head Neck Surg 1996; 122:627-632.

28. Munck-Wikland EM, Fernberg JO, Kuylenstierna R et al. Proliferating cell nuclear antigen(PCNA) expression and nuclear DNA content in predicting recurrence after radiotherapy of early glottic cancer. Oral Oncol, Eur J. Cancer 1993; 29B(1):75-79.

29. Caminero MJ, Nuñez F, Suarez C et al. Detection of P53 protein in oropharyngeal carcinoma. Arch Otolaryngol Head Neck Surg1996; 122:769-772.

30. Nadal A, Campo E, Pinto J, et al - P-53 expression in normal, Dysplastic and Neoplastic Laryngeal Epithelium. Absence of a correlation with Prognostic Factors. J Pathol 1995; 175:181-188.

Endereço para correspondência

Dr. João Paulo Esposito

Rua Alves Guimarães, 643/113

05410-001 — São Paulo-SP 